\title{
The thermodynamic analysis of an electrically supercharged Miller Cycle gasoline engine with early intake valve closing
}

\author{
BIN CHEN ${ }^{1}$, LI ZHANG ${ }^{1, *}$, QUNSHUN LUO ${ }^{1}$ and QING ZHANG ${ }^{2}$ \\ ${ }^{1}$ School of Automotive Engineering, Chongqing University, Chongqing 400044, People's Republic of China \\ ${ }^{2}$ Changan Automobile Co., Ltd., Chongqing 400044, People's Republic of China \\ e-mail: 20153201011@cqu.edu.cn
}

MS received 22 January 2018; revised 20 September 2018; accepted 17 October 2018; published online 18 February 2019

\begin{abstract}
Electric superchargers are able to improve the thermodynamic process of gasoline engines by selfadapting running state to dominate intake air in all operation conditions. This paper proposes a novel approach for electrically supercharged Miller Cycle with early intake valve closing based on thermodynamics to settle the fuel economy problem of gasoline engines at low load operations by taking advantages of the domination of electric superchargers to intake air. Electrically supercharged Miller Cycle with early intake valve closing was realized by matching an electric supercharger, redesigning the inlet cam, and setting the intake valves closing before bottom dead center while keeping intake valves opening constant. An over-expanded engine cycle is attempted to be used to promote thermal efficiency by increasing geometric compression ratio, in addition to maintaining the effective compression ratio. Here, it has been attempted to systematically analyze the law of the energy losses of the electrically supercharged Miller Cycle gasoline engine with early intake valve closing using a reliable thermodynamic model from the perspective of heat engine. The results indicate that electrically supercharged Miller Cycle with early intake valve closing could improve the thermal efficiency of gasoline engines by significantly decreasing the pumping and exhaust losses.
\end{abstract}

Keywords. E-charger; electrically supercharging; gasoline engine; thermal efficiency; Miller Cycle.

\section{Introduction}

Downspeeding and downsizing are effective techniques to deal with increasingly strict standards on vehicle emissions and serious environmental problems caused by engines. Among all the technologies, engine boosting is regarded as a main approach in order to realize downspeeding and downsizing. The concept of electrically supercharging has been extensively proposed, however, its development and application are still challenging by the development of onboard power supply and high-speed motors. Electric superchargers (E-chargers) are flexible and controllable, and they are not confined by engine operations. They can overcome the challenges which are existing in turbochargers and superchargers, thus, they will be able to actively adapt the responsiveness and working state of gasoline engines by adjusting speeds to change pressure ratio based on the actual engine operations. Accordingly, research institutes have not attempted to stop their researches because of technical limitations. Currently, high-speed motors specially used on E-chargers have gained breakthrough [1-5]. With increasingly strict standards on vehicle emissions, a $48 \mathrm{~V}$ onboard electric power system has been

*For correspondence considered to appropriately resolve the issue of power source of E-chargers and provide a good opportunity for the development of electric supercharging systems, accelerating the downspeeding and downsizing of gasoline engines. Honeywell, Caterpillar and Mitsubishi Heavy Industries have carried out lots of researches in the field of electric supercharging, and the results indicated that compared with traditional turbocharging systems, the peak torque and transient responsiveness of the studied gasoline engines were notably improved after matching an electric supercharging system [6-10]. Stapelbroek [11] and Bassett [12], based on the $48 \mathrm{~V}$ onboard electric power system, validated the improvement of vehicle dynamic responsiveness due to the application of E-chargers on the platforms of AMG A45 and Golf GTI. Therefore, electrically supercharging has evident advantage, at the same time, its operation needs to consume engine power, which goes against the improvement of thermal efficiency. In order to solve the problem, Coppin [13] drove an E-charger with recycled braking energy. In addition, Sorger [14] equipped an electric supercharging system using a turbo-generator to recycle exhaust energy, which led solve the problem of power consumption of E-chargers at the expense of increasing engine cost. However, these solutions were contradict to the principle of engine downsizing. 
Miller Cycle [15] which is now widely applied on the hybrid vehicles is a low-cost solution for improving the thermal efficiency of gasoline engines. In Miller Cycle intake valves close before or after bottom dead center, which makes the expansion ratio larger than the compression ratio (CR) which decreases the compression work due to the advancement of intake valve closing, thereby improving the thermal efficiency [16-23]. Endo [24] described the design of a commercially available large scale gas engine working on the Miller cycle and claiming an advantage of more than $5 \%$ over conventional technologies in terms of fuel efficiency. A Miller engine with variable compression ratio (VCR) proved to be much more efficient than the Otto engine for most of the working range, and compared with the Diesel engine, improvements in specific fuel consumption could be noted for most of the speed/load range [25]. Li [26] experimentally compared the effects of early intake valve closing (EIVC) and late intake valve closing (LIVC) on the fuel economy of a boosted direct injection (DI) gasoline production engine reformed with a geometric CR of 12.0 at low and high loads and discussed the mechanism behind the effects of LIVC and EIVC on improving the fuel economy. The results showed that the EIVC strategy results in the smallest absolute pumping mean effective pressure (PMEP) and the lowest rate of heat release while LIVC leads to a higher pressure during the compression stroke. An investigation on the practical range of the EIVC variable valve actuation strategy showed a 7\% improvement in fuel for un-throttled engine operation [27]. A detailed assessment of the main losses carried out by MES Martins indicated that Diesellike engine brake efficiency of more than $40 \%$ could be achieved when applying the Miller Cycle concept [28]. Miller Cycle can improve thermal efficiency while insufficient availability of air that results from the intake valve control strategy results in power loss [29]. Hence, numerous studies have been conducted on the output degradation of Miller-Cycle engines with boosting and have generated many interesting results [30, 31]. The first mass-produced Miller-Cycle engine with delayed closing timing of intake valve and an attached Lysholm Compressor which provided higher boost pressure was put on sale by Mazda [32]. It was capable of avoiding engine knocking while high CR was maintained and had approximately 1.5 times larger torque than that generated by a naturally-aspirated engine of the same displacement.

The literature review shows that the combination of electrically supercharging and Miller Cycle has complementary advantages that enhances the engine power while improves the thermal efficiency. However, there is no research on the combination of these two techniques, and the present researches are based on the external effects, such as power enhancement and reducing fuel consumption. Given that internal engines are the most widely applied heat engine and its nature is energy flow, this paper based on a $2.0 \mathrm{~L}$ gasoline engine proposes a novel technique solution of electrically supercharged Miller Cycle with EIVC, from the perspective of heat engine analyzes the effects of the solution on the law of the energy flow, and reveals the nature of electrically supercharging and Miller Cycle improving performance of the gasoline engine.

\section{Basic technologies and principles}

In this paper, an innovative strategy for electrically supercharged Miller Cycle has been proposed with the help of EIVC system. The combination of electric supercharging and Miller Cycle with EIVC represents complementary advantages, simultaneously enhancing the thermal efficiency, power output, and transient responsiveness by improving the thermodynamic process of gasoline engines. Making intake valves close before bottom dead center generates in-cylinder over-expansion which makes burned gas expands adequately, leading to represent the best usage of the fuel energy. Since, in this study, there is no extra appendix to be employed in gasoline engines, it is compatible with downspeeding and downsizing of gasoline engines.

Figure 1(a) shows the valve timing and p-V diagram of naturally aspirated Miller Cycle gasoline engines with LIVC. As shown in figure 1(a), the intake pressure is lower than the environment pressure $\mathrm{p}_{0}$ and the effective $\mathrm{CR}$ is $\mathrm{V}_{\mathrm{a}} / \mathrm{V}_{\mathrm{c}}$ which is approximately equal to the geometric CR expressed as $\left(\mathrm{V}_{\mathrm{c}}+\mathrm{V}_{\mathrm{s}}\right) / \mathrm{V}_{\mathrm{c}}$. Figure 1 (b) illustrates the valve timing and $\mathrm{p}-\mathrm{V}$ diagram of electrically supercharged Miller Cycle gasoline engines with EIVC. E-chargers can initiatively regulate intake air pressure in terms of engine operations. The effective $C R \mathrm{~V}_{\mathrm{a}} / \mathrm{V}_{\mathrm{c}}$ is lower than geometric $\mathrm{CR}\left(\mathrm{V}_{\mathrm{c}}+\mathrm{V}_{\mathrm{s}}\right) / \mathrm{V}_{\mathrm{c}}$ as intake valves close at point 4 in figure 1(b). As a result, the thermal efficiency could be improved due to the over-expansion effect of working medium.

Currently, the engines with over-expansion used on hybrid vehicles realize a Miller Cycle by delaying closing intake valves. Backflow has been introduced into traditional gasoline engines, however, it might disturb in-cylinder air flow and affect the homogeneousness and turbulence intensity of mixture; consequently, combustion efficiency and thermal efficiency were decreased. The gas flowed back is such a combustible mixture, when it is re-aspirated into a cylinder, the fuel mass injected in the next cycle cannot be controlled precisely due to the oscillation of backflow, accordingly, the combustion and emissions are impacted. Meanwhile, LIVC causes a mass of mixture flow back to intake manifolds, increasing flow losses. In the Miller Cycle with EIVC intake valves close before bottom dead center, there is no backflow and all of the gas aspirated into cylinders is used for operation. Hence, the utilization of intake air has been maximized, while the flow losses decreased as well. 


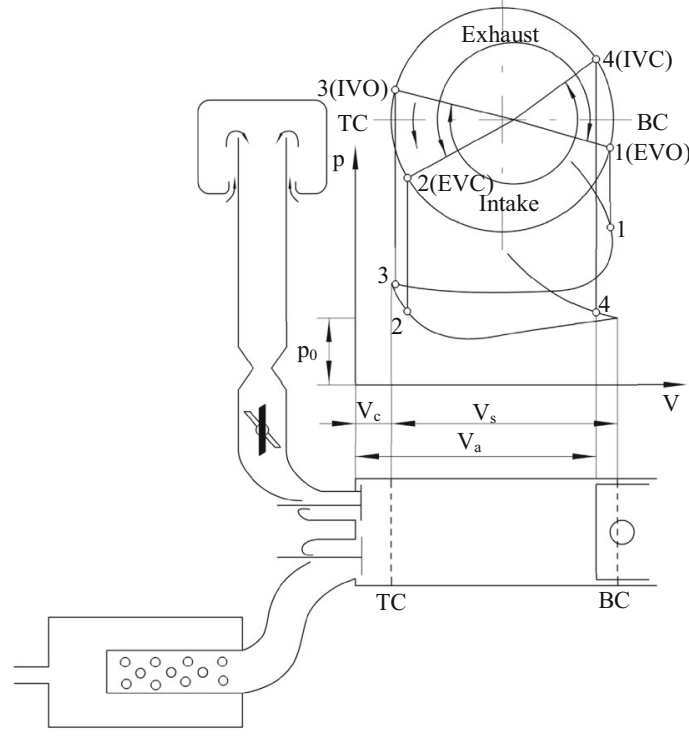

(a) Miller Cycle with LIVC

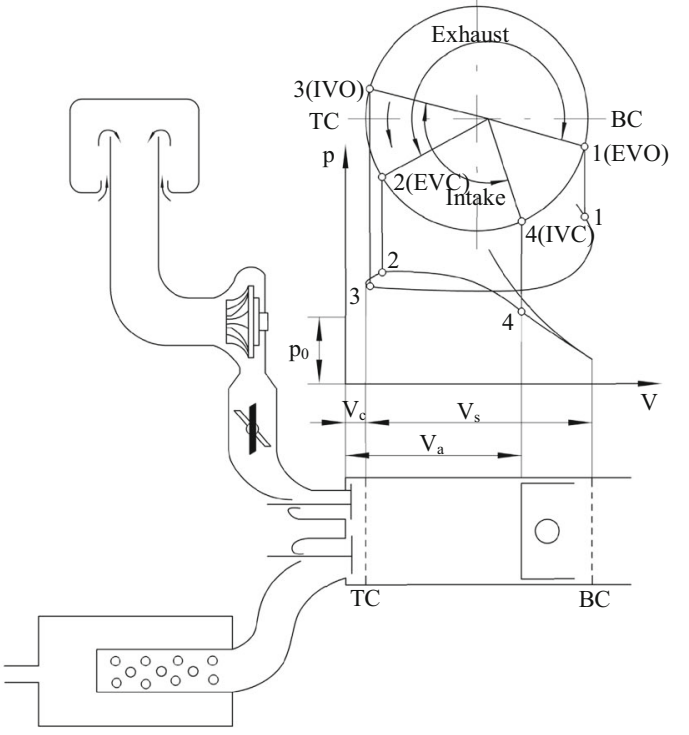

(b) Electrically supercharged Miller Cycle with EIVC

Figure 1. Basic technologies and principles.

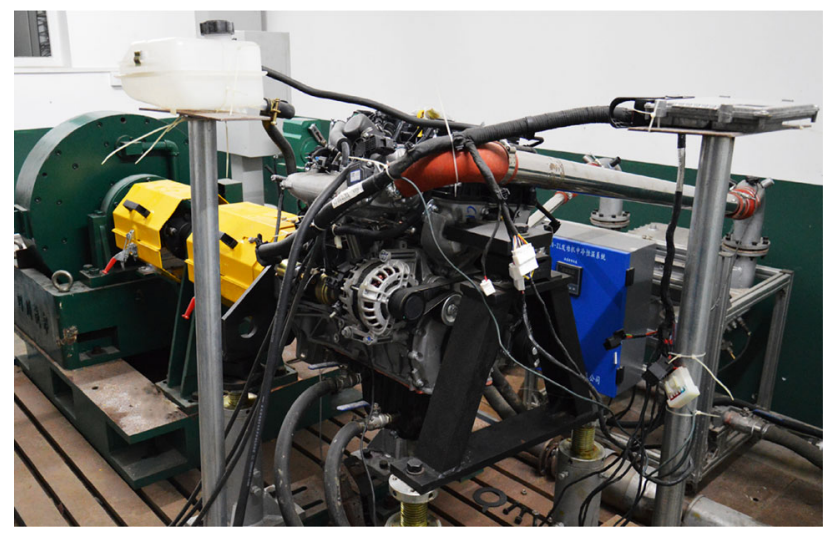

Figure 2. The engine test bench.

\section{Experiment design}

\subsection{Implementation of the proposed strategy}

The basic engine is a $2.0 \mathrm{~L}$ Otto cycle gasoline engine and the experiment was carried out on an engine test bench, as shown in figure 2. In the experiment, three PT100 sensors and three pressure sensors were mounted on the intake pipe to obtain the air temperature and pressure. Two Type-K thermocouple and a pressure sensor were mounted on the exhaust pipe to get the temperature and pressure of exhaust gas. A KISTLER 4958748 contactless torque sensor was mounted on the transmission shaft to precisely measure the power output of the engine. A spark plug type pressure sensor was used to measure in-cylinder pressure. To ensure the accuracy of the measurement results, all values were measured in 200 cycles and averaged. All the signals were

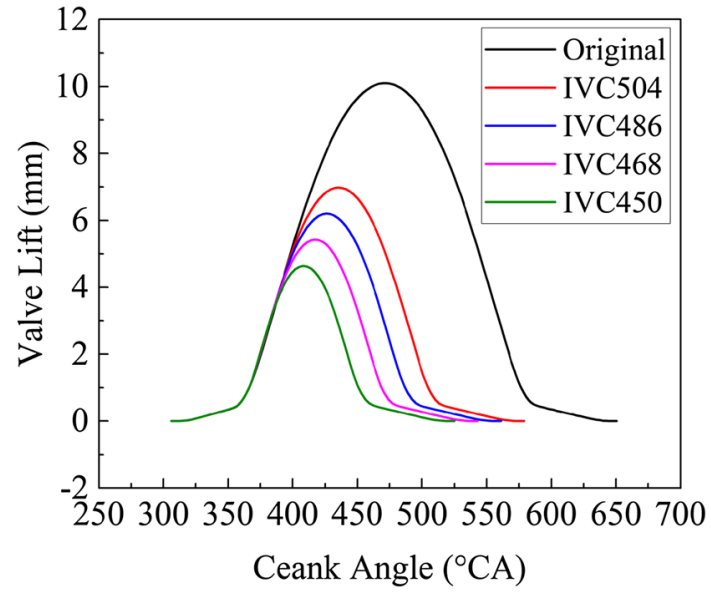

Figure 3. Design of intake valve lift and timing.

collected and processed using a combustion analyzer. In order to realize electrically supercharged Miller Cycle with EIVC, the cams were redesigned by setting intake valve closing before bottom dead center and maintaining intake valve opening, figure 3 shows the principle.

In addition, the intake valve lift was redesigned according to constant acceleration curve, and an E-charger was matched with the basic gasoline engine. The effective CR is defined as the ratio between cylinder volume and clearance volume at the closing moment of all valves. In Miller Cycle, the effective CR decreases with the application of EIVC. The clearance volume was reduced in order to enhance geometric CR for maintaining the effective CR same with that of the basic engine. At middle and low loads, the E-charger did not start and the bypass-valve was 


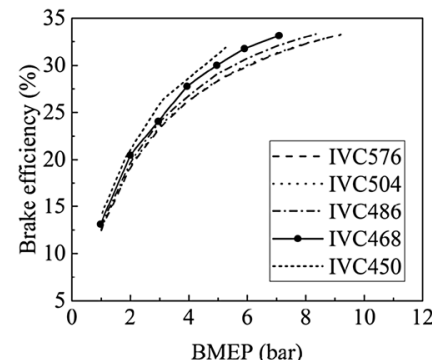

(a) $1500 \mathrm{rpm}$

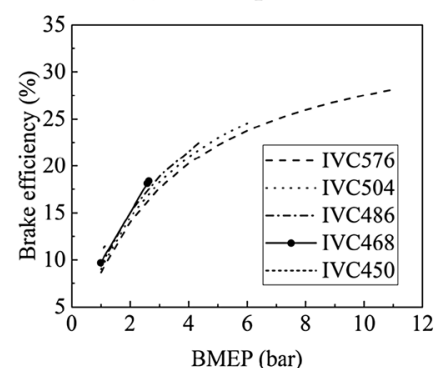

(e) $5500 \mathrm{rpm}$

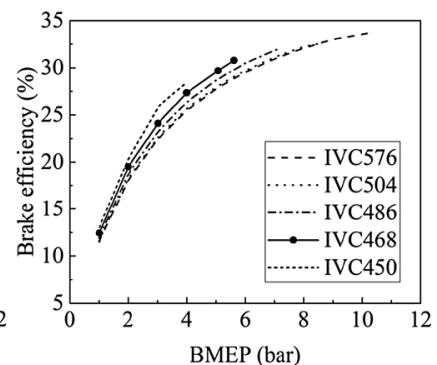

(b) $2500 \mathrm{rpm}$

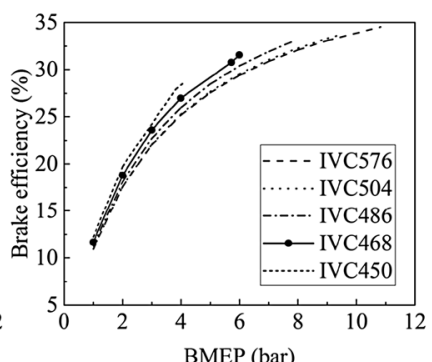

(c) $3500 \mathrm{rpm}$

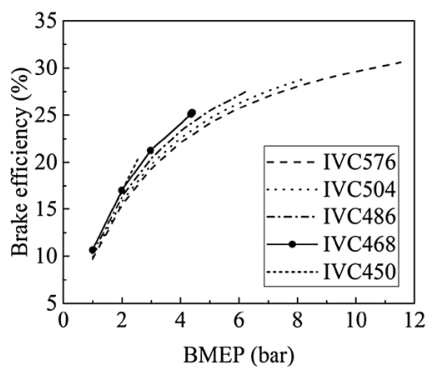

(d) $4500 \mathrm{rpm}$

Figure 4. Matching of intake valve lifts.

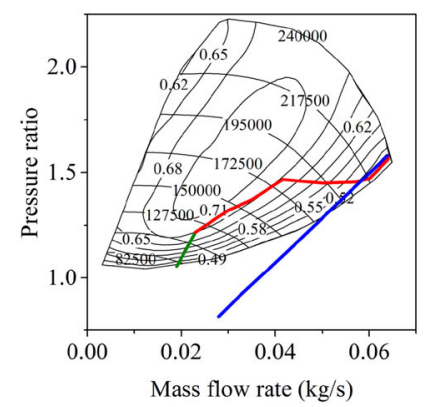

(a) $\mathrm{C} 8-8$

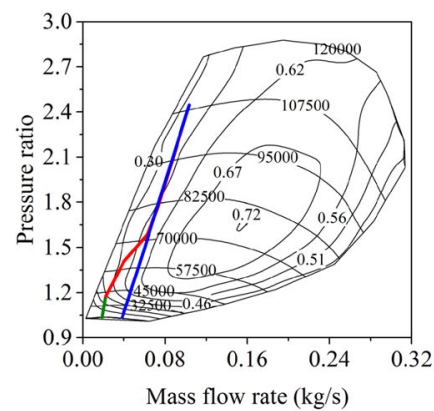

(e) $\mathrm{C} 30-74$

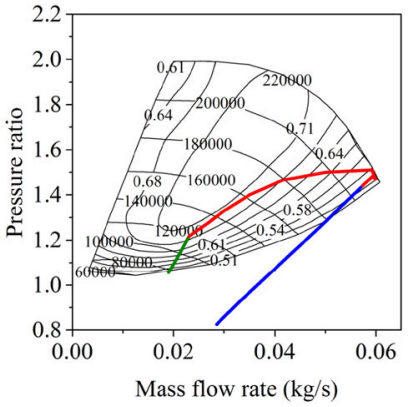

(b) $\mathrm{C} 8 \mathrm{~T}-8$

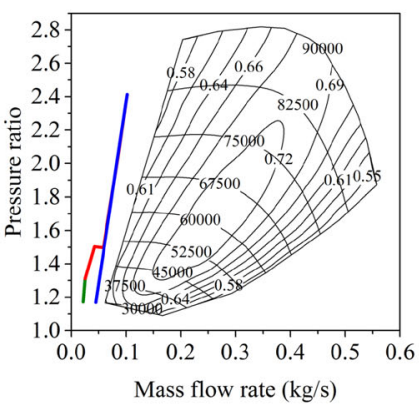

(f) $\mathrm{C} 38-71$

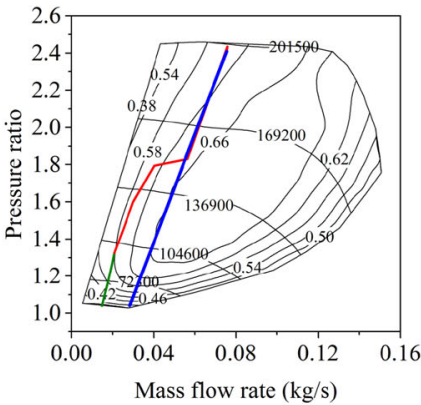

(c) $\mathrm{C} 15-16$

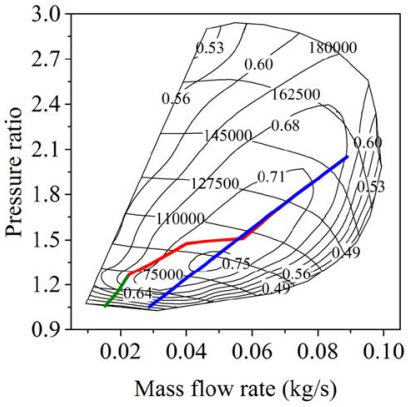

(d) $\mathrm{C} 15-20$

Figure 5. Combined operating maps of E-chargers.

opened, the engine operated in natural aspirating pattern. At high loads, the engine air flow losses increased with the reduction of intake valve lift and duration. Then, in order to satisfy the requirement of the engine for intake air at high load operations, the E-charger started to compress air for compensating the increased air flow losses, consequently, the problem of power output of Miller Cycle engines could be efficiently resolved.

\subsection{Design of intake valve lift and effective $C R$}

Given the wrap angle of intake valves, a phase corresponding to the valve lift of $1 \mathrm{~mm}$ was set as the angle of valve opening and closing. The intake valve closing (IVC) of the basic engine is $576{ }^{\circ} \mathrm{CA}$, calling IVC 576. This is because IVC is often set after bottom dead center about 20- $60^{\circ} \mathrm{CA}$ for making the best of air inertia in 


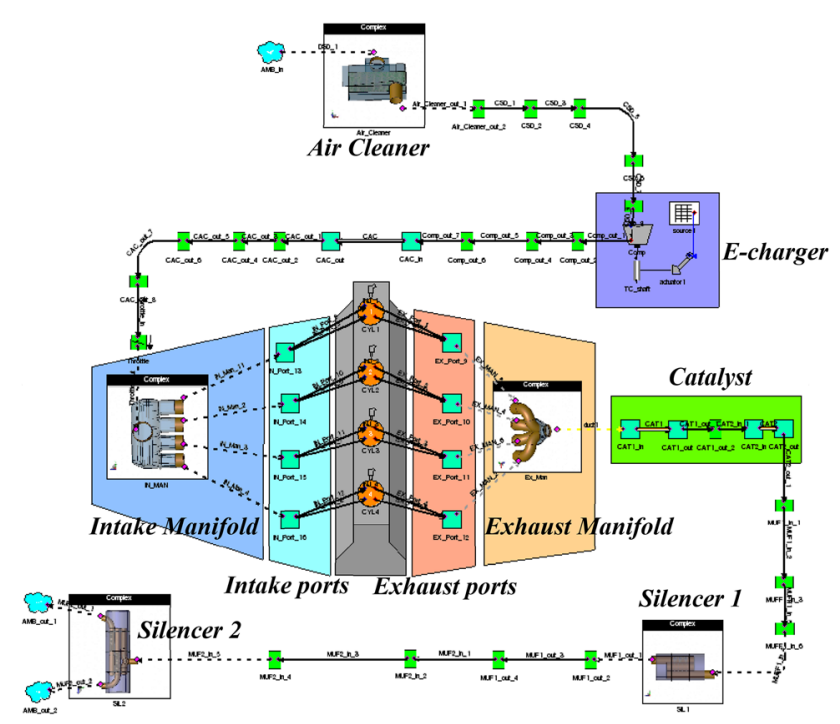

Figure 6. 1-D model of the basic engine built with RicardoWave.

Table 1. Modeling information

\begin{tabular}{lc}
\hline Engine type & Turbocharged, GDI \\
\hline Displacement (L) & 2.0 \\
Number of cylinders & 4 \\
Engine layout & $\mathrm{L}-4$ \\
Compression ratio & $10: 1$ \\
Bore $(\mathrm{mm})$ & 86 \\
Stroke (mm) & 86 \\
Connecting rod length (mm) & 142.8 \\
Cylinder head initial temperature (K) & 400 \\
Piston initial temperature (K) & 520 \\
Cylinder liner temperature (K) & 380 \\
Heat transfer model & WoschniGT \\
Head/Bore area ratio & 1.3 \\
Piston/Bore area Ratio & 1.03 \\
Convection multiplier & 1 \\
Combustion object & SiWiebe \\
Wiebe exponent & 2 \\
Number of temperature zones & Two-temp \\
Fraction of fuel burned & 0.97 \\
Knock model & Douaud \& Eyzat \\
Constant part of FMEP (bar) & 0.4 \\
Peak cylinder pressure factor & 0.006 \\
Mean piston speed factor (bar/(m/s)) & 0.09 \\
\end{tabular}

conventional engines. This study has investigated the Miller Cycle with four different IVCs: IVC 504, IVC 486, IVC 468, and IVC 450 as shown in figure 3, for seeking out the best intake valve plan.

The effective CR reflects the actual compression degree of intake air. The application of Miller Cycle in gasoline engines can represent the effect of effective CR less than geometric $\mathrm{CR}$, and accordingly, the expansion ratio would be larger than effective CR. Moreover, gasoline engines can adopt larger geometric $\mathrm{CR}$ on the condition of keeping effective CR constant.

The basic engine is a four stroke gasoline engine with the geometric CR of 10. The clearance volume, the cylinder volume, and the chamber volume of each cylinder are $0.029 \mathrm{~L}$, $0.5 \mathrm{~L}$, and $0.0265 \mathrm{~L}$, respectively. The minimum volume per cylinder is $0.055508 \mathrm{~L}$ at $0.195{ }^{\circ} \mathrm{CA}$, while the maximum cylinder volume is $0.55506 \mathrm{~L}$ at $180^{\circ} \mathrm{CA}$. The intake valves of the basic engine close at $576^{\circ} \mathrm{CA}$, at this moment, the $\mathrm{Va}$ is $0.5204 \mathrm{~L}$ and the effective $\mathrm{CR}$ is 9.3766 . When intake valves close before bottom dead center $54{ }^{\circ} \mathrm{CA}$, the IVC is called $486{ }^{\circ} \mathrm{CA}$, the $\mathrm{V}_{\mathrm{a}}$ is $0.4789 \mathrm{~L}$, and the corresponding effective $\mathrm{CR}$ is around 8.6288. In order to keep the effective $\mathrm{CR}$ at 9.3766, the combustion chamber was reduced by $0.005 \mathrm{~L}$ and the geometric CR increased to 10.8921 as well. Thereby the geometric CRs are $10,10,10.89,12.51$, and 15.42 respectively when IVCs are $576{ }^{\circ} \mathrm{CA}, 504{ }^{\circ} \mathrm{CA}, 486{ }^{\circ} \mathrm{CA}, 468{ }^{\circ} \mathrm{CA}$, and $450{ }^{\circ} \mathrm{CA}$.

Increasing geometric $\mathrm{CR}$ to keep the same compression degree of intake air is one of the advantages of Miller Cycle. Even though the geometric CR is increased, however, the intake air has the same compression degree, hence, there will not be knock phenomenon. Theoretically, larger geometric CR makes higher thermal efficiency.

\subsection{Matching of intake valve lifts}

Figure 4 shows the matching of intake valve lifts. It is clear that the maximum brake mean effective pressure (BMEP) decreases with the increasing engine speeds, the maximum BMEP is around 0.82 bar at the operation of IVC 450 at $5500 \mathrm{rpm}$ as full load. The brake efficiency increases with the advance of IVC which mainly benefits from the application of larger geometric CR and Miller Cycle. The expansion stroke is larger than the compression stroke in Miller Cycle engines making burned gas to be adequately expanded in order to take full advantages of the released fuel energy, and then the brake efficiency is improved. Taking the brake efficiency, the maximum BMEP, and air flow into consideration, IVC 468 is determined as the research intake valve plan. In the experiment, the brake efficiency was calculated by

$$
\eta_{e t}=\frac{3.6 \times 10^{3} P_{e}}{B H_{u}}
$$

where $P_{e}$ is brake power, $B$ is the specific fuel consumption, $H_{u}$ is the low calorific value of the fuel.

\subsection{Matching of E-chargers}

In this study, there are six alternative E-chargers namely labelled as EC1, EC2, EC3, EC4, EC5, and EC6. As shown in figure 5 , the combined operating map of E-chargers and the basic gasoline engine, involving EC1, EC2 and EC6, are not compatible with the basic engine because of 


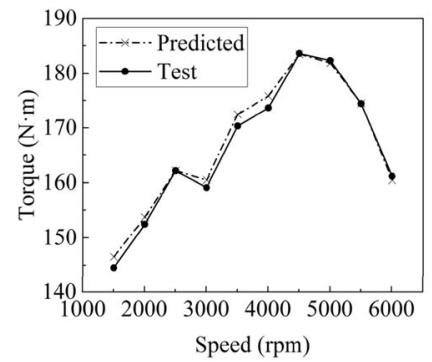

(a) Torque

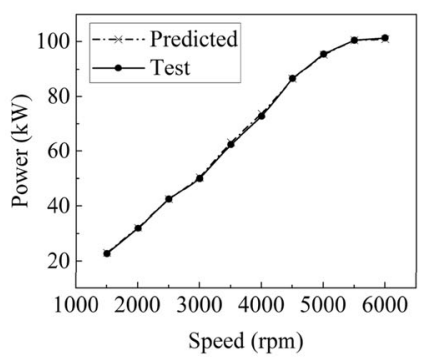

(b) Power

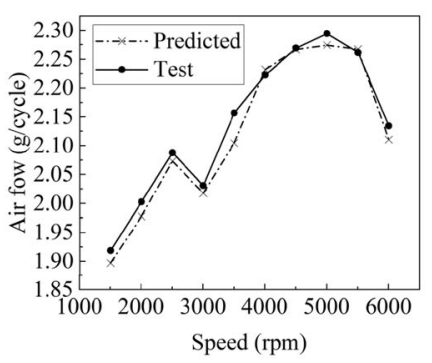

(c) Air flow

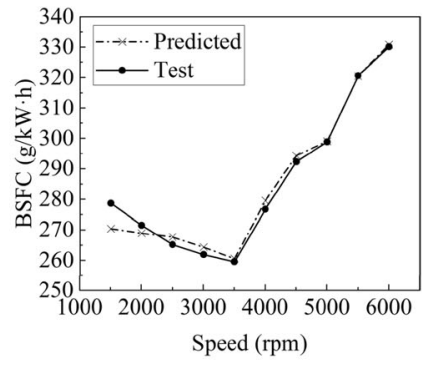

(d) BSFC

Figure 7. Comparisons between predicted and test values.

choking and surging, while EC5 does not operate within the high efficiency regime. At $5500 \mathrm{rpm}$ and full load, some operations of EC3 are close to the map boundary which seems not to be reasonable. The operating state of EC4 which is fully compatible with the basic engine and operates within high efficiency regime is the ideal one.

\section{Mechanism analysis of thermal efficiency improvement}

\subsection{Modeling and validation}

In order to perform thermodynamic analysis, a numerical thermodynamic model was built based on the RicardoWAVE code, as shown in figure 6, and table 1 lists the main parameters of the basic gasoline engine. The operational parameters of the basic engine at all operations were measured on the aforementioned test bench. The actual engine was considered as an assembly of several subsystems, such as intake system, engine body, exhaust system, and so on. The physical models of the subsystems were established with corresponding modes provided by Ricardo-WAVE, and the computing models and the parameters were installed. The E-charger is described by a standard map-based approach, while the flow behavior within the cylinder head and the intake and exhaust pipes is modelled by the flow coefficients experimentally measured by the engine manufacturer. The two-zone Weibe model is adopted to calculate in-cylinder combustion and DouaudEyzat model is embedded to the combustion model to assess knock. For the computation of heat transfer, the most widely applied Woschni model is employed. And a specially developed friction model is employed to calculate friction loss. It is worth mentioning that all the sub-models and boundaries are modified according to experimental values. In order to validate the precision of the built model, the predicted values were compared with test values at various speeds and full load, and the model was repeatedly adjusted.

Figure 7 shows the comparisons of the predicted and the test values. As illustrated in figure 7(a), the deviation of torque is small and the largest deviation is around $1.256 \%$ at $3500 \mathrm{rpm}$. Figure 7(b) indicates that the predicted and the test power are in good agreement. Figure 7(c) demonstrates that the predicted air flow is compatible with the test values regarding the largest deviation of $1.79 \%$ at $6000 \mathrm{rpm}$, meaning that the numerical model can appropriately represent the real air flow of the basic gasoline engine. Figure 7(d) demonstrates that the largest deviation of the predicted and the test brake specific fuel consumption (BSFC) is within $2.5 \%$ at $1500 \mathrm{rpm}$. In conclusion, the predicted values are appropriately compatible with the experimental results, which the corresponding deviation is within $3 \%$. Consequently, the numerical model can truly reflect the operation process of the basic gasoline engine, while further researches on electrically supercharged Miller Cycle with EIVC can be planned and undertaken.

Regarding the analysis of intake valve lifts and matching the E-chargers, the proposed strategy for Miller Cycle was realized by early closing intake valves; the intake valve plan was IVC 468; EC4 was designated as the research E-charger; the geometric CR was 12.51. At middle and low loads, the E-charger did not operate and the bypass valve was opened, while the engine operated in the natural aspirating pattern. At high load operations, the E-charger started to compress air, and the engine operated in the electric supercharging pattern.

\subsection{Improvement of thermal efficiency}

The results presented in figure $8(\mathrm{a}), 8(\mathrm{c}), 8 \mathrm{e}, 8(\mathrm{~g})$, and 8(i) show that the electrically supercharged Miller Cycle with EIVC could improve remarkably the thermal efficiency of the gasoline engine at middle and low loads; the maximum improvement of thermal efficiency at various speeds and loads are $6.51 \%$ at $1500 \mathrm{rpm}$ with 6 bar BMEP, $8.06 \%$ at $2500 \mathrm{rpm}$ with 2 bar BMEP, $7.15 \%$ at $3500 \mathrm{rpm}$ with 3 bar BMEP, $10.06 \%$ at $4500 \mathrm{rpm}$ with 2 bar BMEP, and $11.47 \%$ at $5500 \mathrm{rpm}$ with 1 bar BMEP, respectively. At high speed operations, in order to achieve sufficient power output, the speed and the pressure ratio of the E-charger are enhanced, leading to increase power consumption of the E-charger. Therefore, the improvement of thermal 


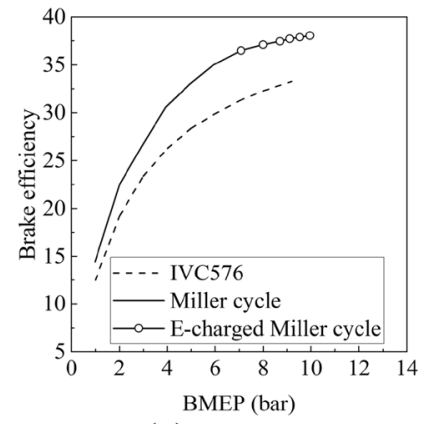

(a) $1500 \mathrm{rpm}$

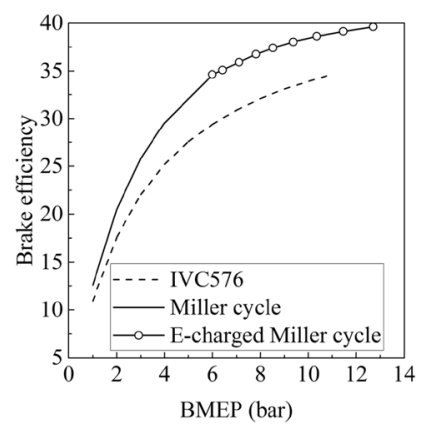

(e) $3500 \mathrm{rpm}$

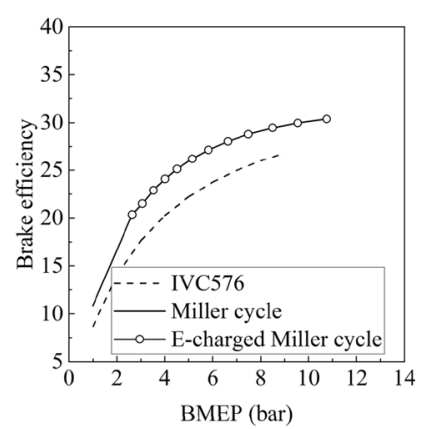

(i) $5500 \mathrm{rpm}$

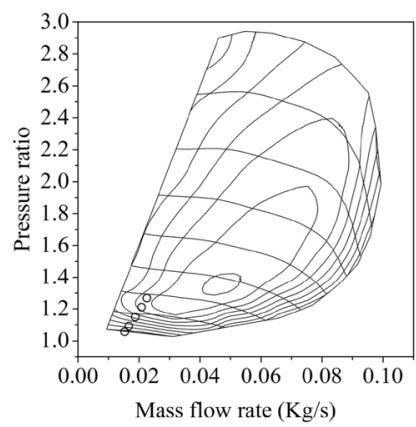

(b) $1500 \mathrm{rpm}$

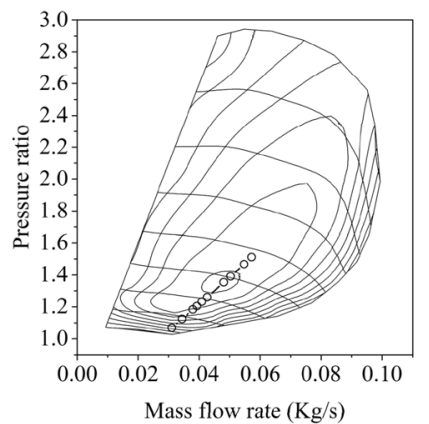

(f) $3500 \mathrm{rpm}$

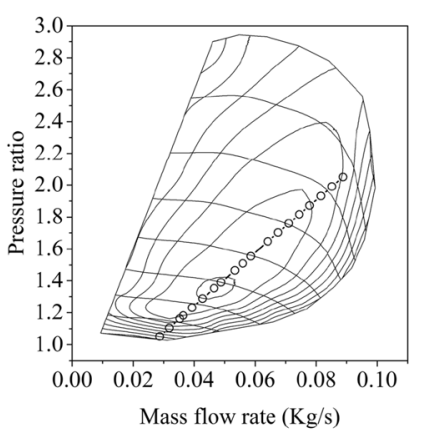

(j) $5500 \mathrm{rpm}$

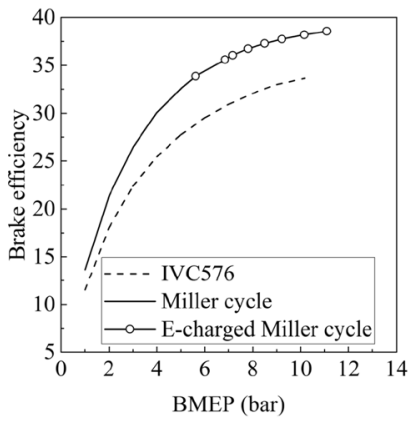

(c) $2500 \mathrm{rpm}$

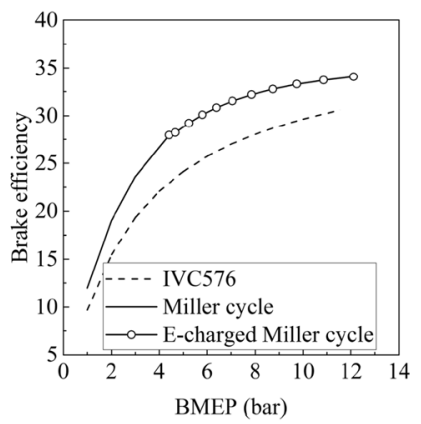

(g) $4500 \mathrm{rpm}$

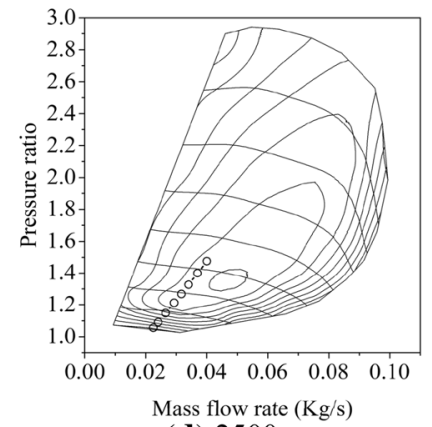

(d) $2500 \mathrm{rpm}$

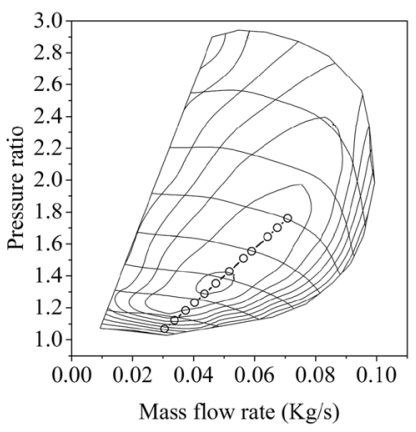

(h) $4500 \mathrm{rpm}$

Figure 8. Results of the proposed strategy

efficiency is limited, and the thermal efficiency is even lower than the basic engine at $5500 \mathrm{rpm}$ with high loads.

Figures $8(\mathrm{~b}), 8(\mathrm{~d}), 8(\mathrm{f}), 8(\mathrm{~h})$, and $8(\mathrm{j})$ represent the combined operating map of EC4 and the gasoline engine at various speeds. It is clear that EC4 operates in a reasonable state with high efficiency and adequate safety margin, therefore EC4 perfectly matches with the gasoline engine.

\subsection{Analyzing the improvement of thermal efficiency}

As shown in figure 10, the exhaust loss rate and pumping loss rate of Miller Cycle in natural aspirating pattern clearly decreases compared with the basic engine as depicted in figure 9. The reductions of the exhaust loss rate are $2.95 \%$,
$3.20 \%, 3.28 \%, 3.34 \%$, and $3.52 \%$ at $1500,2500,3500$, 4500 , and $5500 \mathrm{rpm}$, respectively. This is attributed to the over-expansion effect of Miller Cycle which reduces incylinder temperature and thereby decreases the energy contained in exhaust gas. The reduction of the pumping loss rates are $0.35 \%, 0.50 \%, 0.50 \%, 1.04 \%$, and $1.53 \%$ at 1500 , $2500,3500,4500$, and $5500 \mathrm{rpm}$, respectively, enhancing with the increase of speed and load. A modest increment of the heat transfer loss rate and the friction loss rate can be found. It is also worth mentioning that the increment of the heat transfer loss rate decreases with increasing speed, while the increment of the friction loss rate represents an opposite trend. The increments of the heat transfer loss rate are $1.03 \%, 0.81 \%, 0.70 \%, 0.23 \%$, and $0.17 \%$, while the increments of the friction loss rate are $0.66 \%, 0.98 \%$, $0.94 \%, 1.34 \%$, and $1.17 \%$ at $1500,2500,3500,4500$, and $5500 \mathrm{rpm}$, respectively. 


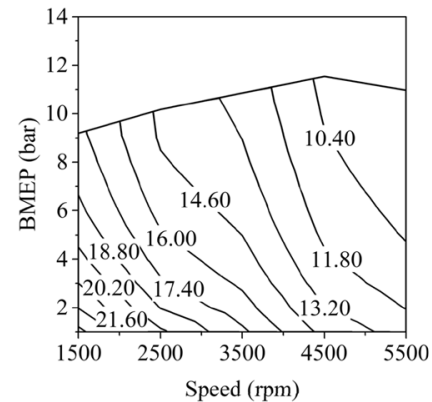

(a) Heat transfer losses

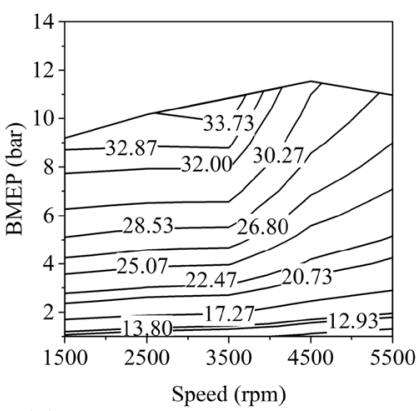

(e) Brake thermal efficiency

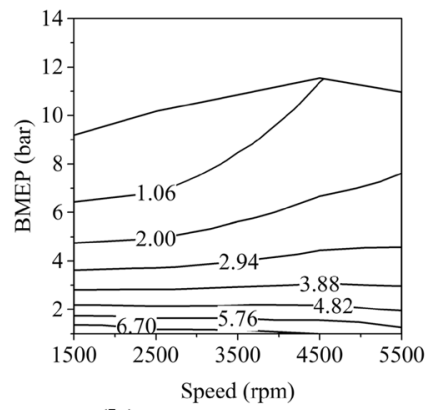

(b) Pumping losses

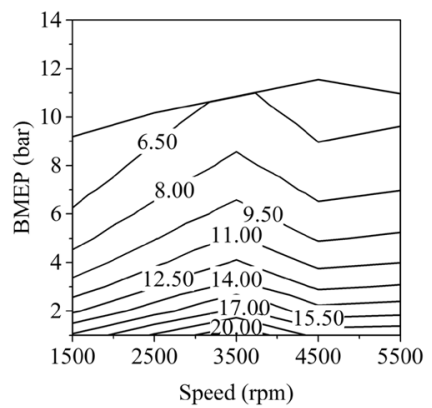

(c) Friction losses

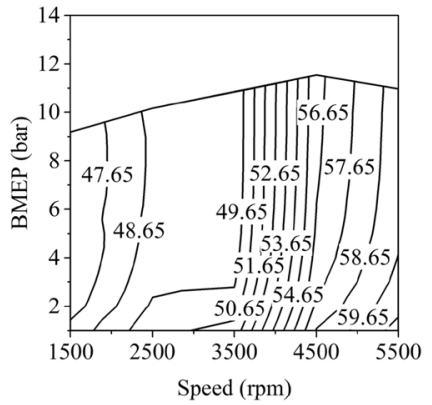

(d) Exhaust losses

Figure 9. Energy flow of the basic engine (\%).

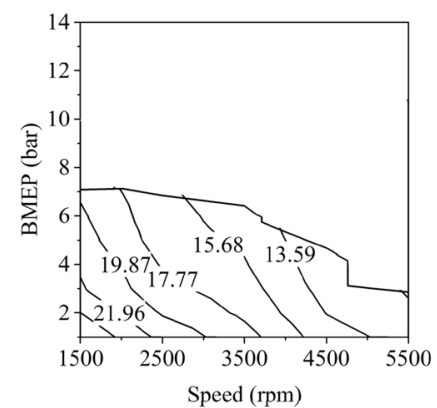

(a) Heat transfer losses

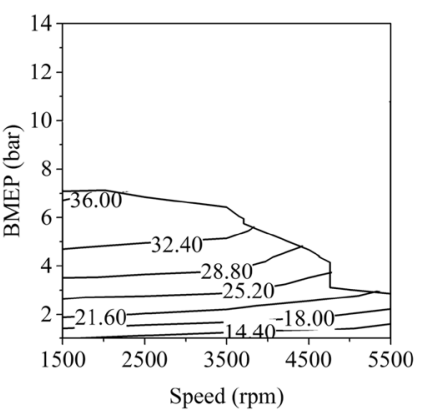

(e) Brake thermal efficiency

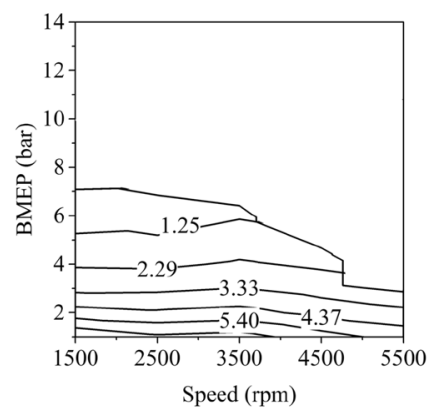

(b) Pumping losses

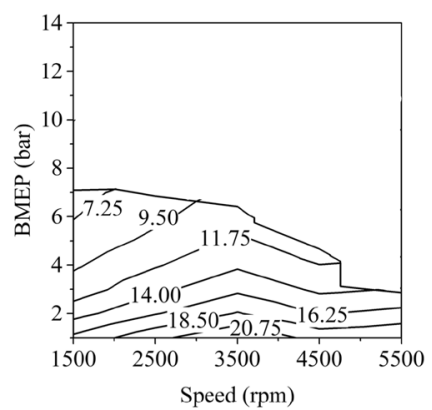

(c) Friction losses

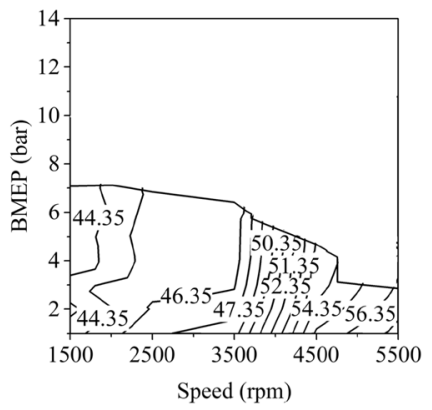

(d) Exhaust losses

Figure 10. Energy flow of the natural aspirated Miller Cycle engine (\%).

\subsection{Analyzing the improvement of thermal efficiency}

As shown in figure 10, the exhaust loss rate and pumping loss rate of Miller Cycle in natural aspirating pattern clearly decreases compared with the basic engine as depicted in figure 9. The reductions of the exhaust loss rate are $2.95 \%$, $3.20 \%, 3.28 \%, 3.34 \%$, and $3.52 \%$ at $1500,2500,3500$, 4500, and $5500 \mathrm{rpm}$, respectively. This is attributed to the over-expansion effect of Miller Cycle which reduces in- 


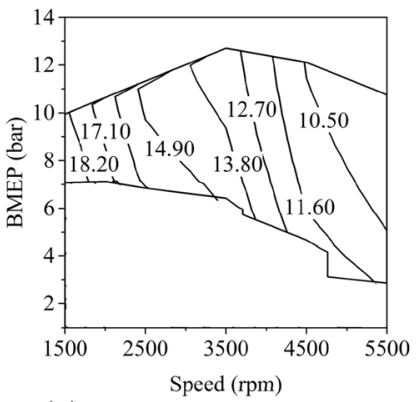

(a) Heat transfer losses

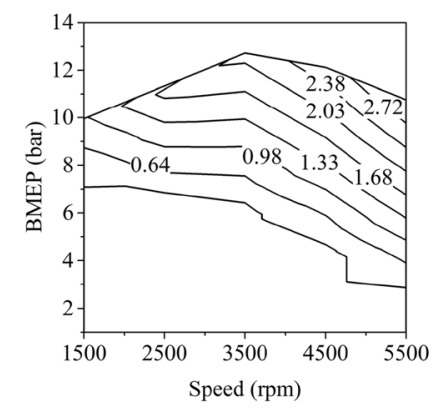

(e) Power consumption of E-charger

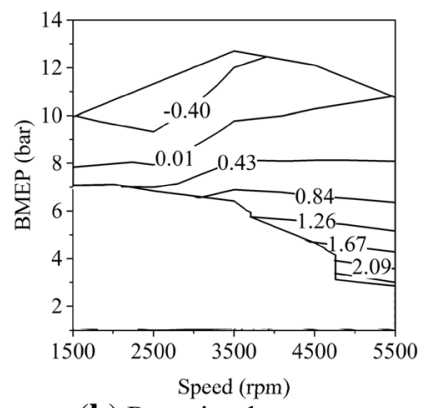

(b) Pumping losses

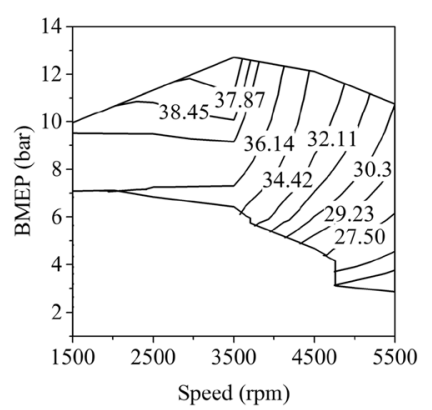

(f) Brake thermal efficiency

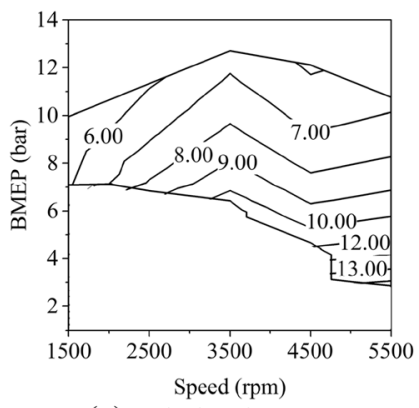

(c) Friction losses

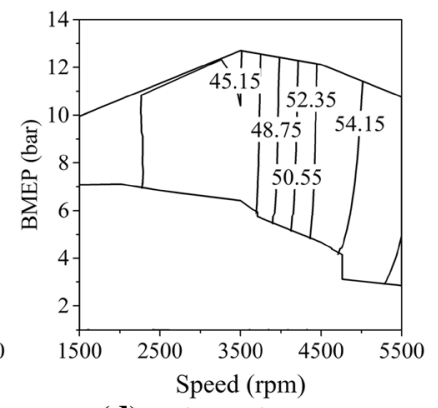

(d) Exhaust losses

Figure 11. Energy flow of the electrically supercharged Miller Cycle engine with EIVC (\%).

cylinder temperature and thereby decreases the energy contained in exhaust gas. The reduction of the pumping loss rates are $0.35 \%, 0.50 \%, 0.50 \%, 1.04 \%$, and $1.53 \%$ at 1500 , 2500, 3500, 4500, and $5500 \mathrm{rpm}$, respectively, enhancing with the increase of speed and load. A modest increment of the heat transfer loss rate and the friction loss rate can be found. It is also worth mentioning that the increment of the heat transfer loss rate decreases with increasing speed, while the increment of the friction loss rate represents an opposite trend. The increments of the heat transfer loss rate are $1.03 \%, 0.81 \%, 0.70 \%, 0.23 \%$, and $0.17 \%$, while the increments of the friction loss rate are $0.66 \%, 0.98 \%$, $0.94 \%, 1.34 \%$, and $1.17 \%$ at $1500,2500,3500,4500$, and $5500 \mathrm{rpm}$, respectively.

Figure 11 summaries the energy flow of the electrically supercharged Miller Cycle with EIVC. At high load operations when the E-charger started to operate, the decrements of the exhaust loss rate are $2.99 \%, 3.32 \%, 3.60 \%$, $3.50 \%$, and $3.61 \%$ at $1500,2500,3500,4500$, and $5500 \mathrm{rpm}$, respectively. It is clear that there is a further reduction in the exhaust loss rate at the electrically supercharging operations, while this decrement is limited. The reductions of the pumping loss rate are $0.34 \%, 0.76 \%$, $0.72 \%, 1.16 \%$, and $1.42 \%$ at $1500,2500,3500,4500$, and $5500 \mathrm{rpm}$, respectively. Comparing with the basic engine, the E-charger significantly reduces the pumping loss rate at middle speed operations, however, the E-charger results in decrement of the pumping loss rate at low and high speed operations. The reduction of the heat transfer loss rate is close to that of the natural aspirating Miller Cycle. The E-charger enhances the decrement of the friction loss rate which is $0.41 \%, 0.66 \%, 0.84 \%, 0.82 \%$ at $1500,2500,3500$, 4500 , and $5500 \mathrm{rpm}$, respectively.

These results demonstrate that the electrically supercharged Miller Cycle with EIVC is able to improve the thermal efficiency of gasoline engines. The mechanism is that the over-expansion of Miller Cycle reduces in-cylinder temperature, thereby decreases the exhaust loss, while the application of E-chargers and larger geometric CR enhances the effect. Eventually, the increase of intake air pressure led to reduce the pumping loss.

\section{Conclusions}

Improving the thermal efficiency of gasoline engines is regarded as a comprehensive problem with correlation with structure, flow, combustion, and control. Reducing energy losses is the fundamental purpose to this issue and all the strategies of improving thermal efficiency manifest as the reduction of one or several energy losses. In this study, an electrically supercharged Miller Cycle gasoline engine with EIVC has been analyzed from the perspective of heat engine. The results revealed the improvement of thermal efficiency of gasoline engines. The variations of pumping, heat transfer, friction, and exhaust losses of the electrically supercharged Miller Cycle gasoline engine with EIVC were fully analyzed using a precise numerical thermodynamic model.

Electrically supercharged Miller Cycle with EIVC could reduce pumping and exhaust losses by dominating intake air and over-expanding working medium, which led to 
improve the thermal efficiency substantially. The mechanism is that the application of electrically supercharged Miller Cycle with EIVC increases air pressure, which led to notably reduce pumping loss, while the reduction of pumping loss enhanced with the increase of speeds and loads. The increment of in-cylinder temperature could reduce exhaust loss, however, the operating state of E-chargers did not represent a substantial effect on exhaust loss. Eventually, the heat transfer and friction losses slightly increased, while the increment contains a trivial effect on the thermal efficiency.

\section{Acknowledgment}

This research work was supported by the Fundamental Research Funds for the Central Universities (Grant No. 106112016CDJXZ338825) of China.

\section{Appendix}

\section{Nomenclature}

CR compression ratio

VCR variable compression ratio

TC top dead center

BC bottom dead center

IVC intake valve closing

EIVC early intake valve closing

LIVC late intake valve closing

DI direct injection

PMEP pumping mean effective pressure

$\mathrm{P}_{\mathrm{e}} \quad$ brake power

B specific fuel consumption

$\mathrm{H}_{\mathrm{u}} \quad$ low calorific value of the fuel

BSFC brake specific fuel consumption

BMEP brake mean effective pressure

\section{References}

[1] Kolondzovski Z, Arkkio A, Larjola J and Sallinen P 2011 Power limits of high-speed permanent-magnet electrical machines for compressor applications. IEEE Trans. Energy Convers. 26: 73-82

[2] Cho H W, Ko K J, Choi J Y, Shin H J and Jang S M 2011 Rotor natural frequency in high-speed permanent-magnet synchronous motor for turbo-compressor application. IEEE Trans. Mag. 47: 4258-4261

[3] Noguchi T, Takata Y, Pyamashita Y, Komatsu Y and Lbaraki S 2010 220,000-r/min, 2-kW PM motor drive for turbocharger. Electr. Eng. 161: 31-40

[4] Lateb R, Enon J and Durantay L 2009 High speed, high power electrical induction motor technologies for integrated compressors. In: Proceedings of the International
Conference on Electrical Machines and Systems, Tokyo, Japan, 15-18

[5] Zhang F, Du G, Wang T, Wang F, Cao W and Kirtley L 2016 Electromagnetic design and loss calculations of a 1.12-MW high-speed permanent-magnet motor for compressor applications. IEEE Trans. Energy Convers. 31: 132-140

[6] Arsie I, Cricchio A, Pianese C, Cesare M D and Nesci W 2014 A comprehensive powertrain model to evaluate the benefits of electric turbo compound (ETC) in reducing $\mathrm{CO}_{2}$ emissions from small diesel passenger cars. SAE Technical Paper 2014-01-1650

[7] Millo F, Mallamo F, Pautasso E and Ganio M G 2006 The potential of electric exhaust gas turbocharging for HD diesel engines. SAE Technical Paper 2006-01-0437

[8] Pullen K R, Etemad S, Thornton W and Villegas J 2012 Electrically driven supercharger using the TurboClaw ${ }^{\circledR}$ compressor for engine downsizing. In: Proceedings of the 10th International Conference on Turbochargers and Turbocharging, London, Britain, 15-16

[9] Nishiwaki K, Iezawa M, Tanaka H, Goto T and An B 2013 Development of High Speed Motor and Inverter for Electric Supercharger. SAE Technical Paper 2013-01-0931

[10] Tavernier S and Equoy S 2013 Design and characterization of an E-booster driven by a high speed brushless DC motor. SAE Technical Paper 2013-01-1762

[11] Sorger H, Schöffmann W, Ennemoser A, Fuckar G, Gröger M, Petutschnig, Teuschl G and Hood J 2016 The Ideal Base Engine for 48 Volts - Chances for Efficiency Improvement and Optimization of the Overall System Complexity. In: Proceedings of the 6th Aachen Colloquium China Automobile and Engine Technology, Peking, China

[12] Hubert A, Mech M I and Bloore P 2016 Benefits of a Switched-Reluctance E-Motor for Mild Hybrid 48V Applications. In: Proceedings of the 6th Aachen Colloquium China Automobile and Engine Technology, Peking, China

[13] Olivier C 2016 12+12V and 12+48V: A Modular Approach for Components and Electric Architectures. In: Proceedings of the 6th Aachen Colloquium China Automobile and Engine Technology, Peking, China

[14] Michael S, Georg B, Matthias T, et al. 2016 Fuel Consumption Reduction and Performance Improvement by Electric Driven Supercharger. In: Proceedings of the 6th Aachen Colloquium China Automobile and Engine Technology, Peking, China

[15] Miller R H 1947 Supercharging and internal cooling cycle for high output. Trans ASME. 69: 453-457

[16] Okamoto K, Zhang F R, Shimogata S, Shoji F, Kanesaka H and Sakai H 1996 Study of a Miller-cycle gas-engine for cogeneration systems effect of a Miller cycle on the performance of a gas engine. SAE Special Publications 1996-361171

[17] Clarke D and Smith W J 1997 Implementation and analysis of the miller cycle using an inlet control rotary-valve, variable valve actuation and power boost. SAE Special Publications 1997

[18] Shimogata S, Homma R, Zhang F R, Okamoto K and Shoji F 1997 Study on Miller cycle gas engine for co-generation systems - numerical analysis for improvement of efficiency and power. SAE Special Publications 1997

[19] Stebler H, Weisser G, Horler H U and Boulouchos K 1996 Reduction of NOx emissions of D.I. diesel engines by 
application of the Miller system: an experimental and numerical investigation. SAE Special Publications 1996-48-1238

[20] Hou S S 2007 Comparison of performances of air standard Atkinson and Otto cycles with heat transfer considerations. Energ. Convers. Manage. 48: 1683-1690

[21] Lin J C and Hou S S 2008 Performance analysis of an airstandard Miller cycle with considerations of heat loss as a percentage of fuel's energy, friction and variable specific heats of working fluid. Int. J. Therm. 47: 182-191

[22] Caton J A 2012 The thermodynamic characteristics of high efficiency, internal-combustion engines. Energ. Convers. Manage. 58: 84-93

[23] Mikalsen R, Wang Y D and Roskilly A P 2009 A comparison of Miller and Otto cycle natural gas engines for small scale CHP applications. Appl. Energ. 86: 922-927

[24] Endo H, Tanaka K, Kakuhama Y,Goda Y Fujiwaka T and Nishigaki M 2017 Development of the lean burn Miller cycle gas engine. In: Proceedings of the 5th International Symposium on Diagnostics and Modeling of Combustion in Internal Combustion Engines, Tokyo, Japan

[25] Ribeiro B and Martins J 2007 Direct Comparison of an Engine Working under Otto, Miller and Diesel Cycles: Thermodynamic Analysis and Real Engine Performance. French History. 23: 360-382
[26] Li T, Gao Y, Wang J and Chen Z 2014 The Miller cycle effects on improvement of fuel economy in a highly boosted, high compression ratio, direct-injection gasoline engine: EIVC vs. LIVC. Energ. Convers. Manage. 79: 59-65

[27] Cleary D and Silvas G 2007 Unthrottled Engine Operation with Variable Intake Valve Lift, Duration, and Timing. In: Proceedings of SAE World Congress \& Exhibition, Detroit, USA

[28] Martins M E S and Lanzanova T D M 2015 Full-load Miller cycle with ethanol and EGR: Potential benefits and challenges. Appl. Energ. 90: 274-285

[29] Mikalsen R, Wang Y D and Roskilly A P 2009 A comparison of Miller and Otto cycle natural gas engines for small scale CHP applications. Appl. Energ. 86: 922-927

[30] Zhu S, Deng K, Liu S and Qu S 2015 Comparative analysis and evaluation of turbocharged Dual and Miller cycles under different operating conditions. Energy 93: 75-87

[31] Hatamura K, Hayakawa M, Goto T and Hitomi M 1997 A study of the improvement effect of Miller-cycle on mean effective pressure limit for high-pressure supercharged gasoline engines. JSAE Rev. 18: 101-106

[32] Choshi M, Asanomi K, Abe H, Okamoto S and Shoji M 1994 Development of V6 Miller cycle engine. JSAE Rev. 15: 195-200 